\title{
Carbon losses from pyrolysed and original wood in a forest soil under natural and increased $\mathbf{N}$ deposition
}

\author{
B. Maestrini ${ }^{1}$, S. Abiven ${ }^{1}$, N. Singh ${ }^{1}$, J. Bird ${ }^{2}$, M. S. Torn ${ }^{3}$, and M. W. I. Schmidt ${ }^{1}$ \\ ${ }^{1}$ Department of Geography, University of Zurich, Winterthurerstrasse 190, 8057, Zurich, Switzerland \\ ${ }^{2}$ School of Earth and Environmental Sciences, Queens College, City University of New York, 11367 , \\ Flushing, New York, USA \\ ${ }^{3}$ Lawrence Berkeley National Laboratory, Earth Science Division, 94720, Berkeley, USA \\ Correspondence to: S. Abiven (samuel.abiven@geo.uzh.ch)
}

Received: 23 October 2013 - Published in Biogeosciences Discuss.: 2 January 2014

Revised: 8 August 2014 - Accepted: 22 August 2014 - Published: 29 September 2014

\begin{abstract}
Pyrogenic organic matter (PyOM) plays an important role as a stable carbon (C) sink in the soils of terrestrial ecosystems. However, uncertainties remain about in situ turnover rates of fire-derived PyOM in soil, the main processes leading to PyOM-C and nitrogen (N) losses from the soil, and the role of $\mathrm{N}$ availability on PyOM cycling in soils.

We measured PyOM and native soil organic carbon losses from the soil as carbon dioxide and dissolved organic carbon (DOC) using additions of highly ${ }^{13} \mathrm{C}$-labelled PyOM (2.03 atom \%) and its precursor pinewood during 1 year in a temperate forest soil. The field experiment was carried out under ambient and increased mineral $\mathrm{N}$ deposition $\left(+60 \mathrm{~kg} \mathrm{~N}-\mathrm{NH}_{4} \mathrm{NO}_{3} \mathrm{ha}^{-1}\right.$ year $\left.^{-1}\right)$. The results showed that after 1 year: (1) $0.5 \%$ of PyOM-C and $22 \%$ of wood-C were mineralized as $\mathrm{CO}_{2}$, leading to an estimated turnover time of 191 and 4 years, respectively; (2) the quantity of $\mathrm{PyOM}$ and wood lost as dissolved organic carbon was negligible $(0.0004 \pm 0.0003 \%$ and $0.022 \pm 0.007 \%$ of applied$\mathrm{C}$, respectively); and (3) $\mathrm{N}$ additions decreased cumulative PyOM mineralization by $43 \%$, but did not affect cumulative wood mineralization and did not affect the loss of DOC from PyOM or wood. We conclude that mineralization to $\mathrm{CO}_{2}$ was the main process leading to PyOM losses during the first year of mineralization in a forest soil, and that $\mathrm{N}$ addition can decrease PyOM-C cycling, while added $\mathrm{N}$ showed no effect on wood C cycling.
\end{abstract}

\section{Introduction}

Pyrogenic organic matter (PyOM) is the product of incomplete combustion of biomass (Goldberg, 1985) and is an important soil $\mathrm{C}$ pool because it can represent up to $45 \%$ of soil organic carbon (Schmidt et al., 1999). Moreover, PyOM input from biomass burning is likely to increase in mid- to high-latitude regions in the future (Westerling et al., 2006; Moritz et al., 2012) because climatic conditions favouring fire are expected to become more frequent. Due to its aromatic structure, PyOM has been hypothesized to be particularly resistant to microbial mineralization (Schmidt and Noack, 2000) and have a centennial mean residence time (MRT) (Schmidt et al., 2011; Singh et al., 2012).

Several recent publications have investigated PyOM mineralization rates under controlled laboratory conditions (Hilscher et al., 2009; Kuzyakov et al., 2009; Santos et al., 2012; Singh et al., 2012b). However, only a few field experiments have been conducted, mainly because the mineralization rate of PyOM is difficult to detect without dedicated techniques such as isotopic tracers and/or biomarkers. In a recent review on PyOM stability Gurwick et al. (2013) identified seven papers estimating PyOM losses in the field. Their review reported substantial uncertainty on the stability of PyOM under field conditions, due to differences in the type of PyOM examined, limitations of the experimental approach and differences in edaphic variables. Most field studies have been observational, comparing the PyOM content of archived soils or chronosequences. Hammes et al. (2008) compared the change in PyOM in a Chernozem sampled twice in a 
100-year interval and found a loss of $25 \%$ using the benzene polycarboxylic acid (BPCA) technique. Using a chronosequence of soils that underwent slash and burn at different times over the last 100 years, Nguyen et al. (2008) reported a $30 \%$ loss of PyOM over 100 years by analysing pre-oxidized handpicked samples using solid state ${ }^{13} \mathrm{C}$ NMR. Schneider et al. (2011) observed no change in the PyOM content of soils that received PyOM deposition for 2 to 100 years. Unfortunately approaches that require a measurement of PyOM within a sediment or soil matrix (e.g. BPCA, NMR, FTIR) rely on biomarkers, which are not exclusive to PyOM and can only be considered semi-quantitative. Furthermore, using archived samples or chronosequences to investigate PyOM stability in soils has several limitations. Archived soils often lack information about the amount of initial amount of PyOM added to the soil or what changes in management or edaphic conditions may have occurred during the mineralization period at the site. Furthermore, it provides no information on the processes that affect PyOM losses or stabilization mechanisms.

An effective approach that overcomes the need to analytically isolate PyOM from soil or rely on archived soil samples is the use of isotopes to directly trace the fate of PyOM-C and $\mathrm{N}$ within soil organic matter pools, within loss pathways, and within organisms over time as well as to partition the $\mathrm{C}$ - and $\mathrm{N}$-derived PyOM from the $\mathrm{C}$ and $\mathrm{N}$ derived from native $\mathrm{SOC}$ pools (e.g. Santos et al., 2012; Kuzyakov et al., 2009). Major et al. (2010) used this approach in a field trial in a tropical savanna. They added PyOM produced from mango trees $\left(\mathrm{C}_{3}\right.$ plant) to a grassland soil in Colombia (soil organic matter derived from $\mathrm{C}_{4}$ plants), and by measuring soil respiration and ${ }^{13} \mathrm{C}_{-} \mathrm{CO}_{2}$ found that $2.2 \%$ of the added PyOM-C was lost as $\mathrm{CO}_{2}$ over two years. The study by Major et al. (2010), who found that losses as DOC were lower than $1 \%$ of the initially added PyOM-C, is the only study, to our knowledge, that has assessed the mineralization and leaching losses of PyOM in the same experiment.

Singh et al. (2012) reviewed PyOM-C mean residence time by compiling a database with results from studies using different experimental designs. One clear message from this analysis was that PyOM-C MRT was longer in field studies than in incubation studies, but the reason for that could not be attributed to a single factor. First, the constant temperature and moisture conditions in the laboratory may increase the mineralization of PyOM-C together with mixing soil and substrate at the beginning of the experiment. Second, the short duration of incubation studies might overestimate turnover time of PyOM, because short-term experiments capture only the initial higher mineralization rate of PyOM (Hamer et al., 2004, Kuzyakov et al., 2009). Singh et al. (2012b) showed in a 5-year incubation experiment that the two pool model may underestimate MRT when applied to short-term incubation.

Third, specific stabilisation processes might need particular climatic conditions, for example freeze-thawing or disaggregation-aggregation, which usually occur under field conditions. The lack of field manipulation experiments does not allow for the disentanglement of this conundrum.

Losses of PyOM from soil have been also shown to occur as dissolved organic carbon (DOC), however there is contrasting evidence on the importance of this pathway for PyOM-C losses. Leifeld et al. (2007) reported that 21-69\% of PyOM moved below the ploughing depth $(30 \mathrm{~cm})$ over at least 50 years in a former agricultural soil where combustion residues were disposed; however, their study was not able to distinguish whether PyOM was transported in soluble or particulate form or both. Singh et al. (2014), who conducted analyses on PyOM recovery in the same experimental setup of the present study, found a translocation rate of PyOM equivalent to $126 \mathrm{~mm}_{\text {year }}{ }^{-1}$, but were not able to distinguish the form of PyOM transported.

Substantial quantities of PyOM have been detected in riverine (Kim et al., 2004) and marine (Dittmar, 2008; Ziolkowski and Druffel, 2010) DOC. Abiven et al. (2011) found that the soluble fraction in PyOM was $1 \mathrm{~g} \mathrm{C} \mathrm{kg}^{-1}$ PyOM-C, while PyOM aged in the field (10 years) contained a much higher fraction of the soluble PyOM, with a value of $41 \mathrm{~g} \mathrm{C} \mathrm{kg}^{-1}$ PyOM-C. Major et al. (2010), reported PyOM losses as DOC of $0.2 \mathrm{~g} \mathrm{C} \mathrm{kg}^{-1}$ PyOM-C over a two-year period. Overall, the lack of data on losses of PyOM-C as $\mathrm{CO}_{2}$ and DOC derived from same experiment leaves the question of the relative importance of the two processes unresolved (Bird et al., 1999; Hammes et al., 2008).

Soil erosion can also cause losses of PyOM from a given location or watershed, mainly due to its low bulk density. For example, Rumpel et al., (2006) found that PyOM-C can represent up to $30 \%$ of eroded carbon in a tropical watershed. However, erosion losses were not determined in the present study.

It has been also observed that PyOM additions to soils may change the turnover rate of the native soil organic carbon (SOC) already present in the soil. PyOM additions to soil have been found to increase (Wardle et al., 2008; Major et al., 2010; Luo et al., 2011), decrease (Liang et al., 2006; Cross and Sohi, 2011) or have no effect (Kuzyakov et al., 2009; Cross and Sohi, 2011; Santos et al., 2012) on the mineralization rate of the native SOC in soils. Keith et al. (2011) found that PyOM increased the mineralization of native SOC and decreased the mineralization of fresh organic matter added with the PyOM. This change in the SOC mineralization rate from added PyOM, also called the priming effect, is an important feedback mechanism than can modify the soil C stocks. Maestrini et al., (2014) reviewed the mechanisms and the size of the priming effect induced by PyOM in a meta-analysis of studies employing stable isotopes. They found that in the literature, positive priming effect (an increase in SOM mineralization) has been related to the presence in PyOM of a labile fraction that triggers various reactions, from microbial activity in soil on the short term (Singh and Cowie, 2014), to PyOM particles serving as a surface 
Table 1. Chemical and physical properties of the soil $(0-15 \mathrm{~cm}$ depth) at the field site, and of PyOM and wood. The values presented are means of three replicates \pm standard errors.

\begin{tabular}{|c|c|c|c|c|c|c|c|c|c|c|c|c|c|c|}
\hline & \multicolumn{3}{|c|}{$\begin{array}{l}\text { Texture } \\
\%\end{array}$} & \multicolumn{3}{|c|}{$\begin{array}{l}\text { Bulk density } \\
\mathrm{g} \mathrm{cm}^{-3}\end{array}$} & \multirow[t]{2}{*}{$\mathrm{pH}$} & \multirow[t]{2}{*}{$\begin{array}{l}\text { CEC } \\
\mathrm{mmol} \mathrm{kg}^{-1}\end{array}$} & \multicolumn{3}{|c|}{$\begin{array}{l}\text { Elemental analysis } \\
\mathrm{g} \mathrm{kg}^{-1} \text { soil }\end{array}$} & \multirow[t]{2}{*}{$\begin{array}{l}\mathrm{C} / \mathrm{N} \\
\text { (mass ratio) }\end{array}$} & \multirow[t]{2}{*}{$\begin{array}{l}{ }^{13} \mathrm{C} \\
\text { (atom \%) }\end{array}$} & \multirow[t]{2}{*}{$\begin{array}{l}\text { Application rate } \\
\left(\mathrm{g} \mathrm{C} \mathrm{m}^{-2}\right)\end{array}$} \\
\hline & Sand & Silt & Clay & $0-5$ & $5-10$ & $10-15$ & & & $\mathrm{C}$ & $\mathrm{H}$ & $\mathrm{N}$ & & & \\
\hline Soil & $\begin{array}{l}45.5 \\
\pm 3.5\end{array}$ & $\begin{array}{l}24.2 \\
\pm 4.4\end{array}$ & $\begin{array}{l}31.5 \\
\pm 2.4\end{array}$ & $\begin{array}{l}\mathrm{cm} \\
1.20 \\
\pm 0.14\end{array}$ & $\begin{array}{l}\mathrm{cm} \\
1.21 \\
\pm 0.32\end{array}$ & $\begin{array}{l}\mathrm{cm} \\
1.60 \\
\pm 0.32\end{array}$ & $5.9 \pm 0.5$ & $74.3 \pm 14.9$ & $\begin{array}{l}33.7 \\
\pm 4.8\end{array}$ & $\begin{array}{l}8.9 \\
\pm 0.7\end{array}$ & $\begin{array}{l}2.4 \\
\pm 0.2\end{array}$ & 14 & & \\
\hline PyOM & & & & & & & & & 799 & 7.1 & 34.3 & 110 & 2.03 & 397 \\
\hline Wood & & & & & & & & & 499 & 4.3 & 66.2 & 115 & 2.05 & 189 \\
\hline
\end{tabular}

for microbial growth (Wardle et al., 2008), to the increased root inputs from plants following PyOM inputs (Major et al., 2010), or to the liming effect of PyOM addition (Luo et al., 2011). A negative priming effect has been explained by the adsorption of organic matter on PyOM surface in a way that protects it from mineralization (Liang et al., 2006; Cross and Sohi, 2011).

In addition to its chemical structure, PyOM mineralization may be affected by other drivers of the ecosystem, such as inorganic nitrogen $(\mathrm{N})$ availability. Increased $\mathrm{N}$ deposition has been observed to have contradicting effects on soil organic matter dynamics, increasing (Burton et al., 2004) or decreasing (Pregitzer et al., 2007) mineralization rates. Where observed, the reduced mineralization of litter has been also explained by a decrease in the activity of ligninolitic enzymes (Carreiro et al., 2000; Sinsabaugh, 2010) which could particularly affect PyOM given its aromatic structure. Alternatively, a shift in the microbial decomposer community toward more efficient C-user microbes has been suggested (Janssens et al., 2010) as being responsible for decreased soil respiration. Jannsens et al. (2010) and Knorr et al. (2005) compiled a meta-analysis on the impact of $\mathrm{N}$ addition on litter decomposition, and found that added $\mathrm{N}$ had an insignificant effect on litter decomposition, if results from different levels of $\mathrm{N}$ addition where pool together. However, Knorr et al. (2005) found a negative effect of $\mathrm{N}$ deposition on litter decomposition when the quantity of added $\mathrm{N}$ was lower than 20 -fold the ambient $\mathrm{N}$ deposition and a stimulative effect for higher levels of $\mathrm{N}$ deposition. Studies carried out specifically on woody litter decomposition in temperate ecosystems disagree with these findings; Bebber et al. (2011) found that $\mathrm{N}$ increased decomposition of woody litter on the short term, while Hagedorn et al. (2012) found that twig decomposition was first increased and then decreased by $\mathrm{N}$ addition.

We added ${ }^{13} \mathrm{C}$-labelled PyOM and ${ }^{13} \mathrm{C}$-labelled wood parent material, Pinus Ponderosa, to the soil of a forest clearing, with two levels of $\mathrm{N}$ addition $\left(0\right.$ and $+60 \mathrm{~kg} \mathrm{~N} \mathrm{ha}^{-1}$ year $\left.^{-1}\right)$ to trace losses of $\mathrm{C}$ as $\mathrm{CO}_{2}$ and as DOC, and to directly estimate priming effect. The focus was on the following research questions: (1) What is the $\mathrm{CO}_{2}$ mineralization rate of PyOM compared to that of the unpyrolysed wood substrate? (2) How much PyOM is lost as DOC? (3) Does PyOM induce a priming effect on native soil organic C? (4) What is the effect of $\mathrm{N}$ deposition on soil $\mathrm{C}$ and PyOM-C fluxes from the soil?

\section{Materials and methods}

\subsection{Field Study}

The field experiment was located in a temperate forest adjacent to a CarboEurope forest tower on the Laegern Mountain (CH-LAE; $47^{\circ} 28^{\prime} 42.0^{\prime \prime} \mathrm{N}, 8^{\circ} 21^{\prime} 51.8^{\prime \prime} \mathrm{E}$; altitude is $700 \mathrm{~m}$ a.s.l., mean annual soil temperature $\left.10^{\circ} \mathrm{C}\right), 20 \mathrm{~km}$ from Zurich, Switzerland. The overstory vegetation consists mainly of beech (Fagus sylvatica L.), spruce (Picea Abies L.), ash (Fraxinus excelsior L.), fir (Abies alba Mill.), and smallleaved lime (Tilia Cordata Mill.), and understory of Allium ursinum (L.) (Ruehr et al., 2009). The soil at the experimental site is a Cambisol (sand: $45 \%$, silt: $24 \%$, clay: $31 \%$ ), rich in organic $\mathrm{C}\left(34 \mathrm{~g} \mathrm{C} \mathrm{kg}^{-1}\right.$, Table 1$)$.

The experimental design was a $3 \times 2$ factorial experiment consisting of three organic input treatments (control - corresponding to no input, wood, and PyOM) and two $\mathrm{N}$ addition levels (ambient and $+60 \mathrm{~kg} \mathrm{~N} \mathrm{ha}^{-1}$ year $^{-1}$ ). The experiment was set-up in three blocks each, containing all the possible combinations of input treatment and $\mathrm{N}$ addition; in other words the experiment was composed of three replicates. The experimental blocks were located in a forest gap of approximately 0.5 ha. We installed 18 mesocosms, each consisting of $20 \mathrm{~cm}$ long, $10 \mathrm{~cm}$ diameter polyethylene cylinders which were inserted in the soil down to a depth of ca. $15 \mathrm{~cm}$ with $5 \mathrm{~cm}$ above the soil surface. Each mesocosm had an open bottom and had two $0.7 \mathrm{~mm}$ mesh-covered "windows" $(4 \mathrm{~cm}$ diameter) placed at distances of 7.5 and $12.5 \mathrm{~cm}$ distance from the bottom. These windows were added to the mesocosms to allow biological, chemical, and climatic equilibration with the external environment, without coarse roots entering. Mesocosms were installed in April 2009 and labelled organic input addition occurred in October 2009.

Any grass and roots growing inside the mesocosms were removed by clipping each time $\mathrm{CO}_{2}$ was sampled (see the section on $\mathrm{CO}_{2}$ efflux) to avoid including autotrophic respiration in the measurements. The installation of the mesocosms in a forest gap was aimed to fairly represent typical 
gap conditions where recent fire-derived PyOM deposition (e.g. climate, sparse vegetation, etc.) is most likely to be seen.

Half of the mesocosms received $\mathrm{N}$ fertilization $(60 \mathrm{~kg} \mathrm{~N}$ $\mathrm{NH}_{4} \mathrm{NO}_{3}$ ha $^{-1}$ year $^{-1}$ ) with $5 \mathrm{Nkgha}^{-1}$ applied every month $\left(10 \mathrm{~kg} \mathrm{Nha}^{-1}\right.$ was applied exceptionally three times to recover the application delay due to the accessibility of the research site). $\mathrm{N}$ was first added to soil in March 2010, 6 months after the application of organic inputs. In each block at a depth of $5 \mathrm{~cm}$ we placed a sensor measuring temperature and soil moisture (5TM soil moisture sensor, Decagon, USA). The data collected prior to March 2010 were thus not affected by the $\mathrm{N}$ fertilization.

\subsection{Organic inputs}

The pine wood and PyOM added to the soil mesocosms were isotopically enriched in ${ }^{13} \mathrm{C}$ (see Table 1). Two-year-old pine saplings (Pinus Ponderosa) were labelled with ${ }^{13} \mathrm{C}-\mathrm{CO}_{2}$ under controlled greenhouse conditions (Bird and Torn, 2006). They were exposed to 10 photoperiods of enriched ${ }^{13} \mathrm{C}-\mathrm{CO}_{2}$ $(10$ atom \%) during the course of their growth. PyOM was produced by pyrolysing the labelled wood at $450^{\circ} \mathrm{C}$ for $5 \mathrm{~h}$ under $\mathrm{N}_{2}$ atmosphere, as described in Santos et al. (2012), mass recovery after pyrolysis was $36 \%$. The PyOM and wood were subsequently milled $(<2 \mathrm{~mm})$ and their $\mathrm{C}, \mathrm{N}$, and ${ }^{13} \mathrm{C}$ content analysed (see Table 1 ). The equivalent of $397 \mathrm{~g}$ $\mathrm{Cm}$ of PyOM and $189 \mathrm{~g} \mathrm{Cm}$ of wood were placed at a soil depth of $1 \mathrm{~cm}$ within mesocosms, and the soil was mixed. The soil in the control mesocosms was also mixed to $1 \mathrm{~cm}$. The detailed chemical composition, structure, and isotopic content of the pine wood and PyOM used in this study are described in Chatterjee et al. (2012). Chatterjee et al. (2012) report that the pyrolysis of wood led to a depolymerisation of hemicelluloses and cellulose which were less present in the char than in the wood. Unfortunately, their study did not allow a conclusion on the fate of ligneous components of wood, which may be partially or totally transformed into new aromatic compounds during the charring process. Yarnes et al. (2011) measured the isotopic enrichment of BPCAs from the PyOM used in this study, and found that the ${ }^{13} \mathrm{C}$ enrichment was similar to the signature of bulk wood and PyOM.

\subsection{Soil respiration}

Soil respiration (SR) was measured 16 times during 1 year using a Li-Cor 8100 equipped with a chamber $(10 \mathrm{~cm}$ diameter, $854.2 \mathrm{~cm}$ volume) on the following sampling dates: 6,13 , 20 November in 2009; 31 March, 8 and 29 April, 18 May, 4 and 22 June, 9 and 20 July, 4 and 26 August, 16 September, 4 October, 4 November in 2010. The hiatus between November and March 2009 is due to snow covering the soil.

Soil respiration was measured three times per mesocosm on each sampling date for $90 \mathrm{~s}$. To allow the re-equilibration of the $\mathrm{CO}_{2}$ concentration between the chamber and the atmosphere measurements were taken 90 seconds apart. At the same time, we also collected samples to measure the ${ }^{13} \mathrm{C}$ enrichment of soil-respired $\mathrm{CO}_{2}$. A Keeling plot approach (Keeling, 1958) was used to estimate the ${ }^{13} \mathrm{C}$ enrichment of the soil-respired $\mathrm{CO}_{2}$ and to calculate the ${ }^{13} \mathrm{C}$ excess efflux from enriched PyOM and wood C (Torn et al., 2003). An $800 \mathrm{~cm}^{3}$ chamber was placed on top of the mesocosms and $\mathrm{CO}_{2}$ was sampled with a syringe three times at regular $9 \mathrm{~min}$ intervals while the $\mathrm{CO}_{2}$ increased. To produce each Keeling plot we took three gas samples, collected after $0,4.5$, and $9 \mathrm{~min}$, corresponding to a total average interval of $246 \mathrm{ppm}$ between the gas sample taken at minute 0 and the one taken at minute 9. Pataki (2003) shows that the error in the intercept due to the narrow range of the $\mathrm{CO}_{2}$ analysed (i.e. the difference in $\mathrm{CO}_{2}$ concentration between the highest and the lowest point) drops after exceeding the $50 \mathrm{ppm}$ interval, meaning that the quality of the Keeling plots is much higher above these $\mathrm{CO}_{2}$ concentration ranges. We analysed the distribution of the $\mathrm{CO}_{2}$ ranges in our Keeling plot (see Fig. 4 in the Supplement) and found that $90 \%$ of our Keeling plots had a range higher than $60 \mathrm{ppm}$, therefore we are confident that closing the chambers for a longer period of time would have led only to a minor decrease of the uncertainty in the intercept. We sampled $17 \mathrm{~mL}$ of gas from the chamber, which was injected into a $12 \mathrm{~mL}$ vial (Exetainer, Labco, United Kingdom) using overpressure as suggested in Joos et al. (2008). Prior to sampling, the gas vials were flushed with $\mathrm{N}_{2}$ three times, and stored under $\mathrm{N}_{2}$. The ${ }^{13} \mathrm{C}$ enrichment of the $\mathrm{CO}_{2}$ samples was measured using an isotope ratio mass spectrometer (IRMS) (Delta-S, Finnigan MAT- Thermofscher scientific, Waltham, USA). Keeling plots were accepted if $r$ of the regression line was higher than 0.9 , if $r^{2}<0.9$ the data were discarded. Where data for ${ }^{13} \mathrm{C}-\mathrm{CO}_{2}$ in control treatments were missing due to technical failure, they were replaced by the average of the same day of the corresponding natural abundance, unamended plots according to Major et al. (2010).

\subsection{Dissolved organic carbon}

Suction lysimeters (multilayer borosilicate $1 \mu \mathrm{m}$ pore $10 \mathrm{~cm}$ diameter, Ecotech, DH) were placed at the bottom of the mesocosms (at a depth of $15 \mathrm{~cm}$ ) and kept under constant vacuum at 650 to 750 mbars. Soil water was collected 9 times over the study period, on the following dates: 27 November, and 17 December in 2009, 14 January, 26 February, 13 May, 22 June, 24 August and 26 November in 2010.

Water samples were filtered using a $0.45 \mu \mathrm{m}$ cellulose acetate membrane. $\mathrm{DO}^{13} \mathrm{C}$ measurement failed on two dates (27 May and 22 June) and since not enough material was left to repeat the measurement, these two sampling dates were discarded. The solution $\mathrm{pH}$ and electrical conductivity were measured (Metrohm, $620 \mathrm{pH}$ meter, Switzerland, and WTW tetracon, 325, Austria) and samples after filtration stored at $4{ }^{\circ} \mathrm{C}$ for maximum of 3 weeks. Total organic carbon content was measured on a $20 \mathrm{~mL}$ subsample of the leachate. A 
Table 2. Average total $\mathrm{C}$ losses over the study period \pm standard error $(n=3)$. The losses as DOC and DOC from the added inputs correspond to the cumulated losses over a year. The losses as $\mathrm{CO}_{2}$ and DOC from the added input are calculated using Eq. (3). Letters indicate where treatments are significantly different (pairwise paired $t$ test, $p<0.05$ ).

\begin{tabular}{lllll}
\hline & Total DOC & $\begin{array}{l}\text { Cumulated losses from } \\
\text { the added input as DOC }\end{array}$ & $\begin{array}{l}\text { Total losses as } \mathrm{CO}_{2} \\
(\% \text { initial input-C })\end{array}$ & $\begin{array}{l}\text { Cumulated losses over } \\
1 \text { year from the added } \\
\text { input as } \mathrm{CO}_{2} \\
(\% \text { initial input })\end{array}$ \\
\hline $\begin{array}{l}\text { Ambient } \mathrm{N} \\
\text { Control }\end{array}$ & $2.1 \pm 0.7 \mathrm{a}$ & & $503 \pm 100 \mathrm{a}$ & \\
PyOM & $1.8 \pm 0.3 \mathrm{a}$ & $0.0004 \pm 0.0003 \mathrm{a}$ & $653 \pm 21 \mathrm{a}$ & $0.54 \pm 0.07 \mathrm{a}$ \\
Wood & $1.7 \pm 0.3 \mathrm{a}$ & $0.022 \pm 0.007 \mathrm{~b}$ & $726 \pm 189 \mathrm{a}$ & $22 \pm 3 \mathrm{~b}$ \\
$\begin{array}{l}\text { Increased } \mathrm{N} \\
\text { Control }\end{array}$ & $1.5 \pm 0.2 \mathrm{a}$ & & $638 \pm 33 \mathrm{a}$ & \\
$\begin{array}{l}\text { PyOM } \\
\text { Wood }\end{array}$ & $1.6 \pm 0.6 \mathrm{a}$ & $0.0002 \pm 0.0001 \mathrm{a}$ & $650 \pm 119 \mathrm{a}$ & $0.28 \pm 0.07 \mathrm{c}$ \\
\hline
\end{tabular}

second subsample of $60 \mathrm{~mL}$ was freeze-dried after removing potential carbonate by lowering $\mathrm{pH}$ to $2.8 \pm 0.1$. Freeze-dried DOC (2-4 mg) samples were analysed for total $\mathrm{C}$ using an elemental analyser (Shimatzu, Asi-v, Kyoto, Japan) and ${ }^{13} \mathrm{C}$ enrichment was measured with an IRMS (Delta-S, Finnigan MAT- Thermofscher scientific, Waltham, USA), coupled to an elemental analyser (EA 1100, Carlo Erba, Italy). Where data for $\mathrm{DOC}$ and $\mathrm{DO}^{13} \mathrm{C}$ were missing due to technical failure to calculate cumulated values, they were replaced by the average of the same day of the corresponding treatment. If the fraction derived from the substrate (Eq. 1) was below 0 , then this was set to 0 .

\subsection{Calculations}

The partitioning of the $\mathrm{CO}_{2}$ and DOC fluxes between native SOM-derived and organic-input-derived wood and PyOM was calculated using Eq. (1) from Balesdent and Mariotti (1996):

$$
\begin{aligned}
& f=1-\left(\delta^{13} \mathrm{C}_{\mathrm{mix}}-\delta^{13} \mathrm{C}_{\text {organic input }}\right) / \\
& \left(\delta^{13} \mathrm{C}_{\text {control }}-{ }^{13} \delta \mathrm{C}_{\text {organic input }}\right),
\end{aligned}
$$

where $f=$ fraction of $\mathrm{CO}_{2}$ flux derived from the organic input; $\delta^{13} \mathrm{C}_{\text {mix }}=$ the isotopic signature of soil-respired $\mathrm{CO}_{2}$ or DOC in organic input treatments, $\delta^{13} \mathrm{C}_{\text {organicinput }}=$ the isotopic signature of the added organic inputs (PyOM and wood), and $\delta^{13} \mathrm{C}_{\text {control }}=$ the isotopic signature of soil $\mathrm{CO}_{2}$ or DOC in the control treatment. The priming effect, i.e the change in native SOM mineralization due to the organic input was calculated for each sampling date as in Eq. (2):

$\mathrm{PE}=\left(\mathrm{SR}_{\text {native }}-\mathrm{SR}_{\text {control }}\right)$,

where $\mathrm{SR}_{\text {control }}=$ soil respiration in the control treatment and $\mathrm{SR}_{\text {native }}=$ mineralization rate of the native soil organic $\mathrm{C}$ in PyOM or wood treatment, calculated as $\mathrm{SR}_{\text {total }}-\left(\mathrm{SR}_{\text {total }} \times f\right)$ where SR substrate is the total soil respiration in the substrate treatment.

To interpolate soil respiration between sampling dates, we modelled the $\mathrm{CO}_{2}$ fluxes according to the method proposed by Fang and Moncrieff (2001) (Eq. 3). Kammer et al. (2011) successfully applied this model to the same site area as our study, and Ruehr et al. (2009) showed that the soil moisture affects soil respiration only when moisture is lower than 15 volume $\%$. Soil moisture was always higher than this value during our study period, so soil moisture dropped out of our model and soil respiration was calculated as

$\mathrm{SR}_{\text {interpolated }}=a \times\left(T-T_{\min }\right) \times b$,

where $T=$ the soil temperature $\left({ }^{\circ} \mathrm{C}\right)$ measured at a depth of $5 \mathrm{~cm}$ ( $30 \mathrm{~min}$ measurement interval), $\mathrm{T}_{\min }$ is the temperature at which SR is supposed to be 0 (in this case fixed to $-20^{\circ} \mathrm{C}$ ) $a$, and $b$ are model parameters calculated for each single mesocosm. The simulated soil respirations for different treatments are shown in Fig. 1. PyOM mineralization measurements were linearly interpolated between sampling dates using Eq. (4) assuming that the fraction derived from PyOM varied linearly between dates:

PyOM mineralization rate $=\mathrm{SR}_{\text {interpolated }} \times f_{\text {interpolated }}$,

where $f_{\text {interpolated }}$ values were calculated by interpolating between subsequent sampling date values obtained from Eq (1) as in Ngao et al. (2005) and Kammer and Hagedorn (2011). The modelled soil respiration (Fig. 1) and the fraction derived from the labelled organic substrate in the period November 2009-March 2011 in the increased N deposition treatments were made equal to the ones occurring under ambient $\mathrm{N}$ in the corresponding period to stress the effect of $\mathrm{N}$ addition.

We fitted the initial and the remaining quantity (Table 2) of PyOM at the end of the experiment, calculated by cumulating values from Eq. (4), to a first-order decay model to 

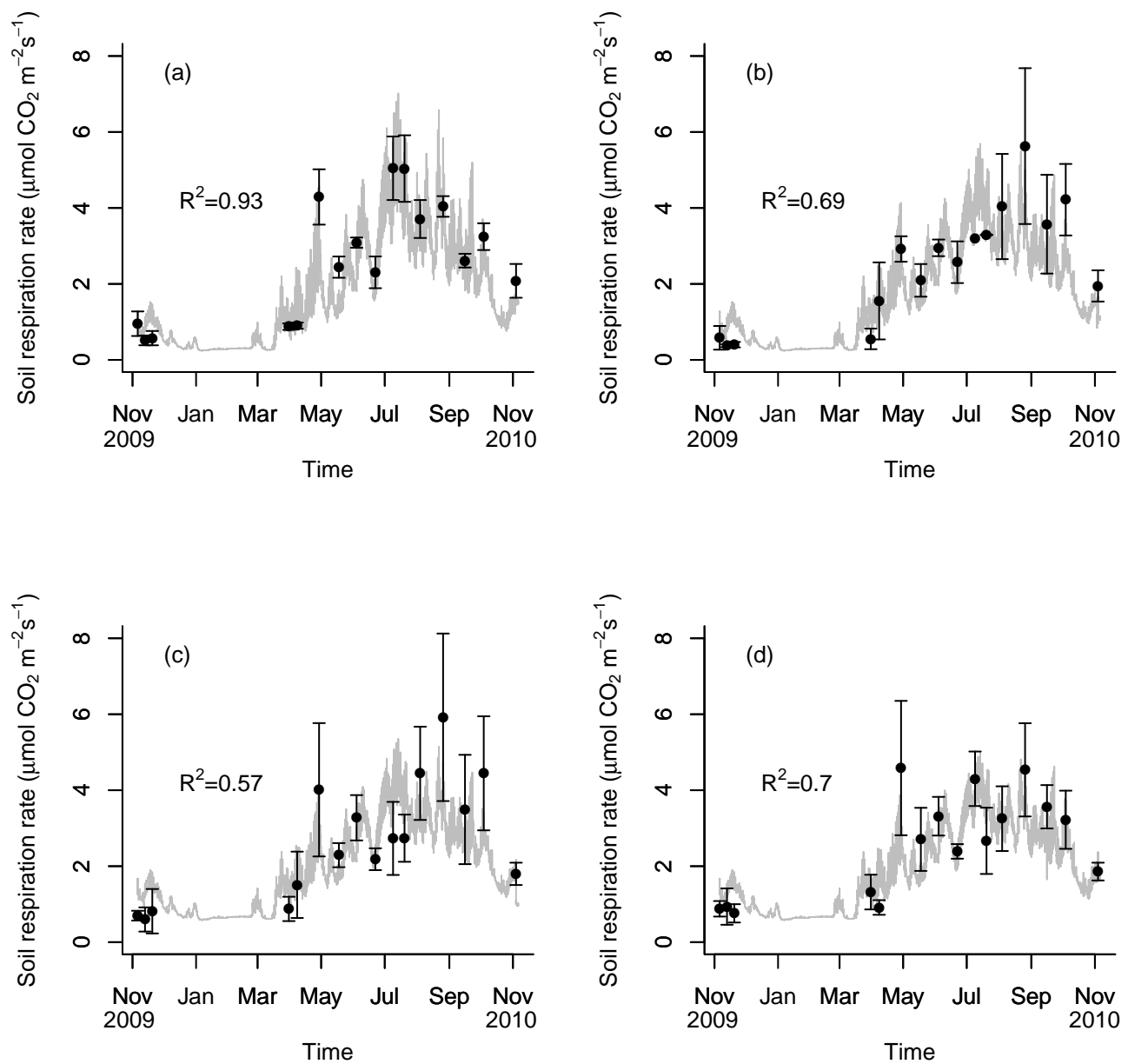

Figure 1. Measured (full symbols) versus modelled (continuous line) soil respiration rate (in $\mu \mathrm{mol} \mathrm{CO}_{2} \mathrm{~m}^{-2} \mathrm{~s}^{-1}$ ), for PyOM under ambient $\mathrm{N}$ (a), PyOM under increased N (b), wood under ambient N (c) and wood under increased N (d). Error bars represent the standard error of the mean $(n=3)$ of the measured soil respiration.

estimate the MRT of PyOM and pine wood, to allow comparison among studies adopting different models as in Singh et al. (2012). Mineralization at time $t$ in the first-order decay model is expressed as follows:

$-\mathrm{d} C / \mathrm{d} t=k \times C_{t} \frac{-\mathrm{d} C}{\mathrm{~d} t}=k C$,

where $C$ is the size of PyOM-C or the wood-C pool. From this formula it is possible to derive the pool size at time $t$ using Eq. (6), assuming that the inputs to the system were equal to 0 and that losses as DOC were negligible:

$C_{t}=C_{t=0} e^{-k t}$,

where $k$ is the constant decay rate, and then calculate the MRT, for each mesocosm as

$\mathrm{MRT}=1 / k$.

Using mineralization model described in Eq. (5), we calculated the ratio between the $C$ still present in soil in the form of
PyOM-C (including losses during pyrolysis) and the quantity of $C$ present in soil from the initial substrate, as calculated by Herath et al. (2014, Eq. 4):

$C$ debit or credit ratio: Remaining $\mathrm{PyOM}_{t}(\%) /$

Remaining feedstock- $\mathrm{C}_{t}(\%)$,

where Remaining PyOM-C ${ }_{t}(\%)$ is the quantity of $C$ still present in soil at time $t$, including losses by pyrolysis, and Remaining feedstock- $\mathrm{C}_{t}(\%)$ is the quantity of $C$ from the initial substrate remaining from substrate at time $t$.

\subsection{Statistical analyses}

The effects of treatment, $\mathrm{N}$ addition, and time were tested on the following variables: soil respiration, the fraction derived from added substrate in soil respiration and DOC, DOC daily production rate, soil water conductivity and soil water $\mathrm{pH}$, using repeated measures ANOVA and individual ANOVA procedures on individual sampling dates. 


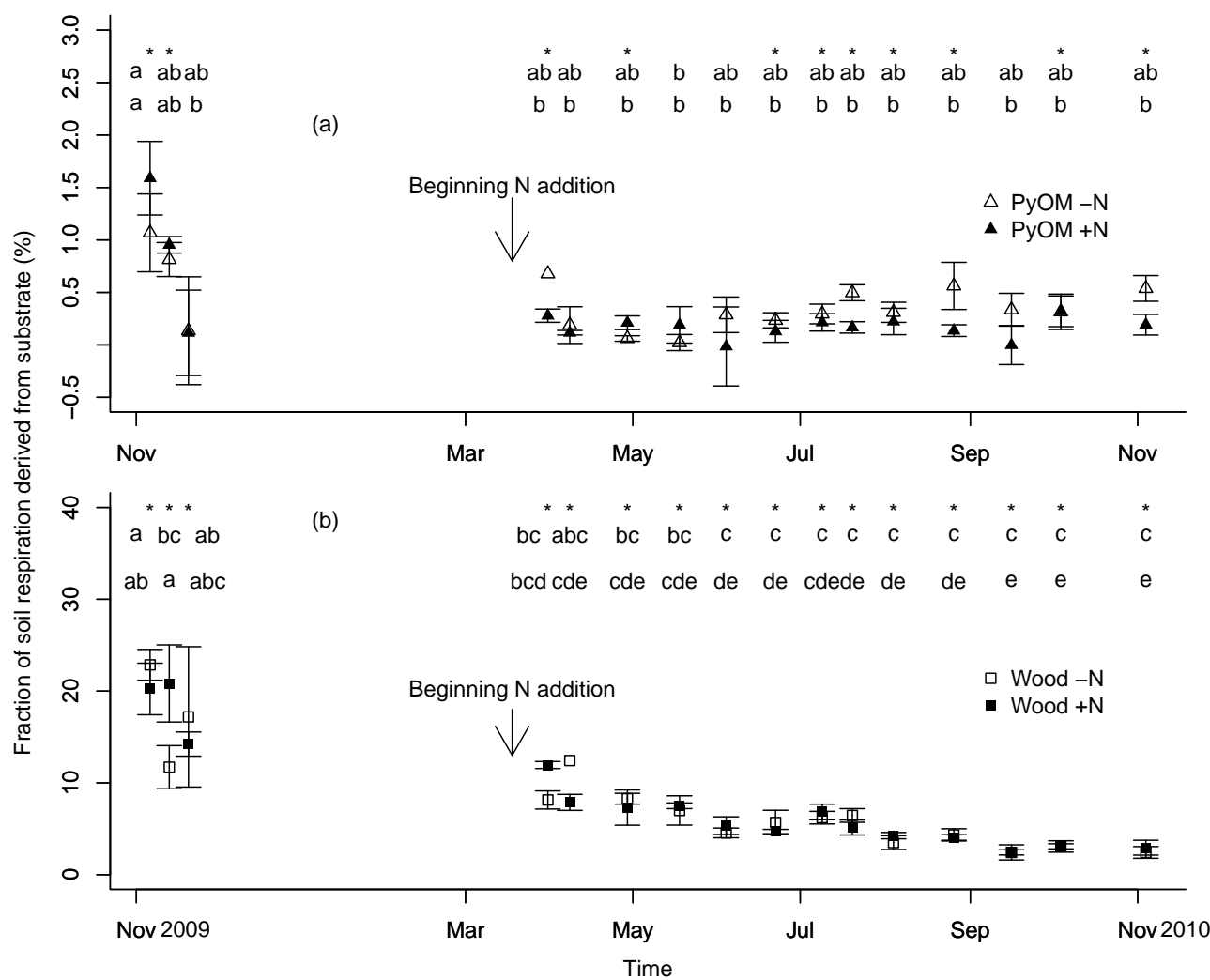

Figure 2. Fraction of soil respiration derived from PyOM (a) and from wood (b). The sampling dates within the same treatment with different letters (on the top) are significantly different ( $p<0.05$ TukeyHSD test). The first line of letters refers to the ambient N treatment and the second to the increased $\mathrm{N}$ treatment. Error bars represent the standard error of the mean $(n=3)$. Asterisks $\left(^{*}\right)$ indicate when the fraction is significantly different from 0 (ambient and increased $\mathrm{N}$ treatment were pooled together, $n=6, P<0.05$ ).

Two different repeated measures ANOVA were performed: one over the time period November 2009November 2010 to test the effect of different organic inputs and time as well as their interactions, and another was performed over the period March 2010-November 2010 (during the $\mathrm{N}$ addition period, started in March 2010). Individual comparisons within the same organic treatment and the $\mathrm{N}$-addition treatment were performed using Tukey's comparison to test differences among sampling dates.

T-tests were performed on individual sampling dates (ambient and increased $\mathrm{N}$ treatment pooled together) to test whether the fraction derived from $\mathrm{CO}_{2}$ was significantly different from 0 .

A repeated measures ANOVA was performed using SPSS Statistics v.18 (IBM, New York, USA) and Tukey's comparison tests were performed using $R$ (version 2.10), extended by the "agricolae" package.

\section{Results}

\subsection{Soil respiration rates, organic input mineralization, and priming effect}

The average soil respiration rate (SR) in the control treatment (no additions) during the year was $2.0 \pm 0.1 \mu \mathrm{mol} \mathrm{CO}_{2} \mathrm{~m}^{-2}$ $\mathrm{s}^{-1}$. Neither $\mathrm{N}$ nor organic input addition significantly affected the soil respiration rates, whereas time did, with higher respiration rates measured in July and September (repeated measures ANOVA $p<0.001$; Fig. 1 and Supplement Fig. S1).

The fraction of soil respiration derived from the substrate was significantly higher in the wood treatment than in PyOM for all sampling dates (post-hoc Tukey test $P<0.05$, Fig. 2). Nitrogen addition did not have a significant effect on the fraction of $\mathrm{CO}_{2}$ derived from the added substrate. The ${ }^{13} \mathrm{C}$ isotopic enrichment of $\mathrm{CO}_{2}$ is reported in Supplement Fig. S5.

Under ambient $\mathrm{N}$, the fraction of soil respiration derived from PyOM on 6 November 2009 was significantly different from that measured on 18 May 2010. Under increased $\mathrm{N}$, during the period March 2010-November 2010, we observed no differences in the PyOM-derived fraction of soil 


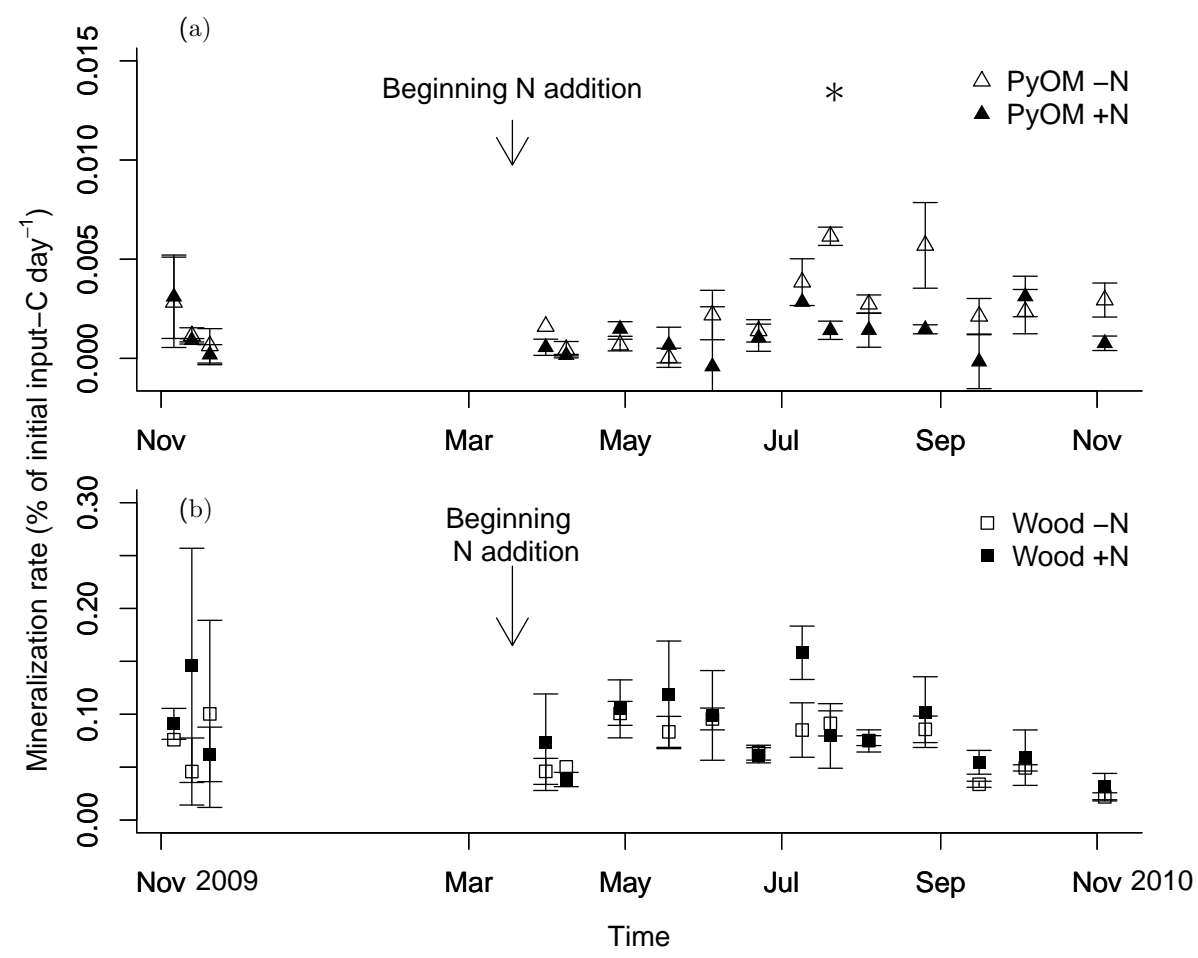

Figure 3. Mineralization rate (in $\mu \mathrm{mol} \mathrm{CO} \mathrm{CO}^{-2} \mathrm{~s}^{-1}$ ) of wood (a) and PyOM (b). Empty symbols represent the treatment under ambient $\mathrm{N}$ and full symbols under increased N. Asterisks $\left(^{*}\right)$ indicate the dates when the addition of $\mathrm{N}$ significantly affected substrate mineralization (paired $t$ test, $P<0.05)$. Error bars represent the standard error of the mean $(n=3)$.

respiration among sampling dates (post-hoc Tukey test $P<$ 0.05; Fig. 2a).

For the wood treatment under ambient $\mathrm{N}$, the woodderived fraction of 6 and 20 November 2009 was significantly higher than the one measured between June and November 2010. Under increased N, during the period March-November 2010, only the fraction derived from wood on 31 March was significantly different from the ones following (post-hoc Tukey test $P<0.05$; Fig. 2b).

The PyOM mineralization rate was on average $0.0022 \pm 0.0003 \%$ and $0.0011 \pm 0.0002 \%$ of PyOM-C day $^{-1}$ added under ambient and increased $\mathrm{N}$, respectively. Wood mineralization rate was $0.077 \pm 0.008 \% \mathrm{day}^{-1}$ and $0.081 \pm 0.008 \%$ day $^{-1}$ of wood-C added under ambient and increased $\mathrm{N}$, respectively.

Overall, the effects of added $\mathrm{N}$ on added litter loss as respired $\mathrm{CO}_{2}$ was minor. Only on 20 July did the sampling $\mathrm{N}$ addition significantly decrease the loss of PyOM as $\mathrm{CO}_{2}$ compared with ambient $\mathrm{N}$ (Fig. 3). Wood mineralization as $\mathrm{CO}_{2}$ was not affected by $\mathrm{N}$ addition on any sampling date (Fig. 3).

The $\mathrm{CO}_{2}$ respiration rate of native soil organic $\mathrm{C}$ was not significantly affected by either the addition of the organic inputs or the addition of $\mathrm{N}$; i.e. no significant positive or negative priming was observed (Fig. 4, repeated measures ANOVA, $P<0.05$ ). However, under ambient $\mathrm{N}$ the PyOM- induced priming effect tended to be positive. Total soil $\mathrm{CO}_{2}$ respiration rates were unaffected by added wood, PyOM or $\mathrm{N}$ (Table 2).

We estimated the cumulative quantity of PyOM-C and wood-C lost as $\mathrm{CO}_{2}$ during the 10-month period using EQ. (4). PyOM-C losses were $0.5 \pm 0.1 \%$ of the initial PyOM-C and the wood-C losses were $22 \pm 3 \%$ of initial wood-C input. $\mathrm{N}$ addition significantly decreased the PyOMC mineralization to $0.3 \pm 0.1 \%$, $(t$ test, $P<0.05)$, while wood mineralization was not affected by $\mathrm{N}$ addition (Supplement Fig. S2, Table 2). The MRT calculated according to Eq. (7) was $191 \pm 24$ and $430 \pm 146$ years for PyOM-C for ambient and increased $\mathrm{N}$, respectively, and $4 \pm 1$ years for Wood-C for both ambient and increased $\mathrm{N}$ treatment.

We estimated the ratio between the $C$ present in PyOM and the $C$ present in the feedstock over 5 years (Supplement Fig. S8), and found that the $C$ remaining in PyOM form (including losses by pyrolysis) would be more than that still present in the initial feedstock after 2.3 years.

\subsection{Dissolved organic carbon}

Total DOC production did not significantly differ among treatments, nor did leachate $\mathrm{pH}$, conductivity, or volume (Figs. S6 and S7). The fraction of DOC derived from the substrate was significantly greater from wood than PyOM (repeated measures ANOVA, $P<0.05$ ), under increased and 


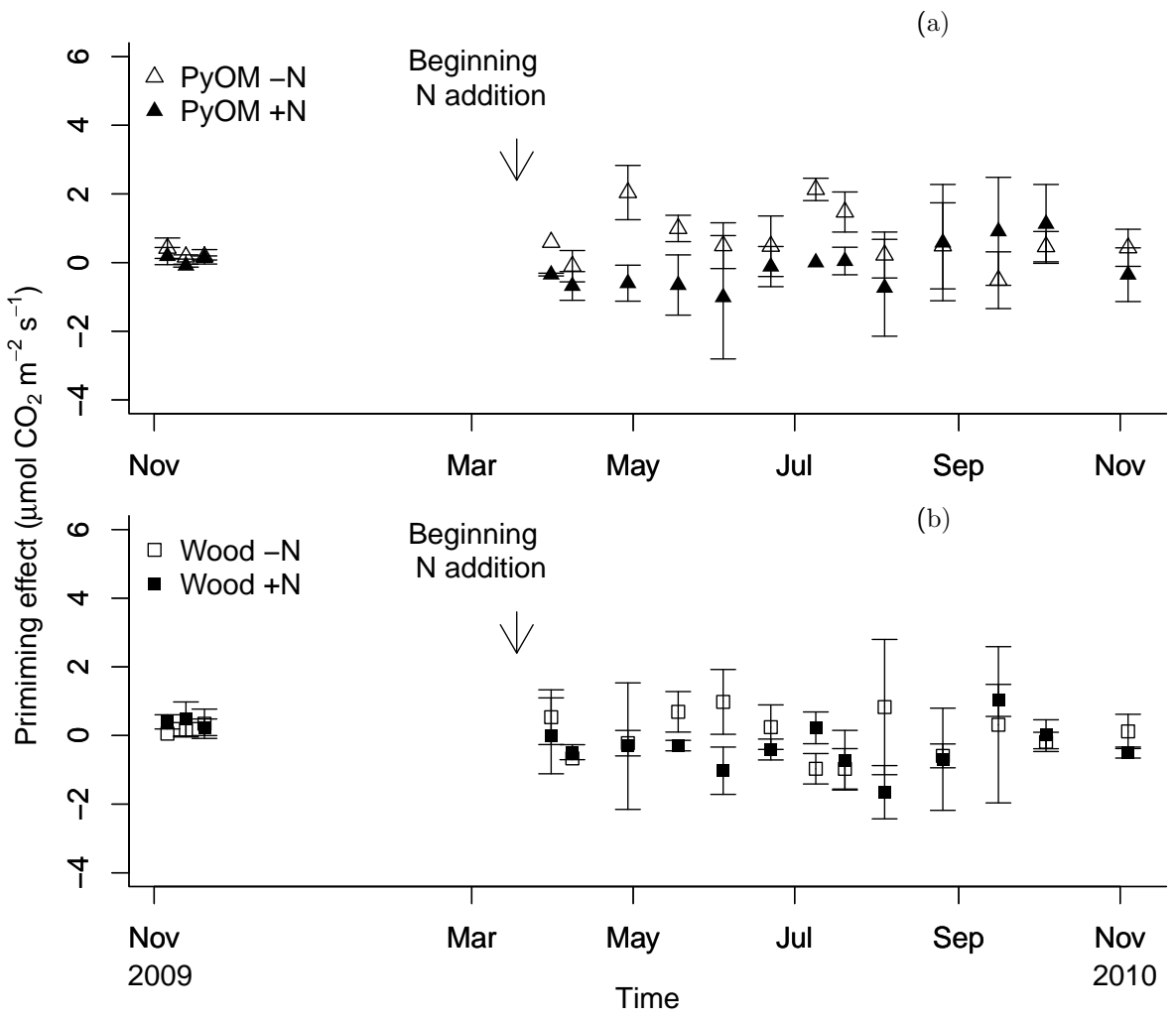

Figure 4. Priming effect induced by PyOM (a) and wood (b) in $\mu \mathrm{mol} \mathrm{CO} \mathrm{CO}^{-2} \mathrm{~s}^{-1}$, derived from Eq. (2). Unshaded symbols represent the treatment under ambient $\mathrm{N}$ and the black symbols represent the treatment under increased $\mathrm{N}$. Error bars represent the standard error of the mean $(n=3)$.

under ambient $\mathrm{N}$. Volume-averaged $\mathrm{d}^{13} \mathrm{C}$ values of DOC are reported in Supplement Table S1.

Cumulative losses of PyOM-C as DOC were $0.0004 \pm 0.0003 \%$ of the initial input-C, while wood$\mathrm{C}$ losses were $0.022 \pm 0.007 \%$ of the wood-C, and under increased $\mathrm{N}$ addition losses were $0.0002 \pm 0.0001 \%$ for PyOM, and $0.03 \pm 0.01 \%$ for wood (Supplement Fig. S3; Table 2). Nitrogen did not affect the cumulative losses of DOC neither in the PyOM and nor in the wood treatment.

\section{Discussion}

\subsection{PyOM and wood mineralization}

We estimated PyOM turnover time in a field experiment under excluded root conditions to be $191 \pm 24$ years, while wood had a turnover time of $4 \pm 1$ years. PyOM turnover time in our field study was higher than the turnover time for wood-derived PyOM found in incubation studies (Hamer et al., 2004; Hilscher et al., 2009, Singh et al., 2012). Singh et al. (2014) measured the recovery of PyOM in the same experiment and found that PyOM losses were lower than $1 \%$, in agreement with our findings, however the decrease in PyOM recovery observed in their study was not statistically significant. After 10 months they also observed a change in the chemical quality of PyOM. They measured the relative content of the different benzene polycarboxylic acids (a biomarker specific to PyOM) in the soil was changed, and observed a decrease of the contribution of the highly condensed rings (B6CA). Nonetheless, at the present stage it is not possible to conclude if the decrease of the relative contribution of the different rings can be related to the mineralization of PyOM (Singh et al., 2014).

Using the same substrate in an incubation experiment, Santos et al. (2012) found a mineralization rate of $0.39 \%$ of initially added $\mathrm{C}$ after 180 days compared to $0.08 \%$ of initially added C in our study after 180 days (Fig. 2 Supplement). An increased turnover time for PyOM mineralization than observed in the laboratory incubation studies indicate that higher and more constant temperature and soil moisture conditions are likely to increase the mineralization rate of PyOM compared to our field studies, whose mean annual soil temperature was $10^{\circ} \mathrm{C}$ and moisture was 30 volume $\%$.

In order to allow a comparison of our study with similar studies reporting the PyOM loss rate in the field we transformed their observed mineralization rate into a mean residence, assuming a single pool mineralization model based on the initial and final PyOM content (Singh et al., 2012). 
Our PyOM MRT is closer to the values reported by Nguyen et al. (2008), who found a MRT of 264 years under tropical climate, and from Hammes et al. (2008) who found a MRT of 347 years in a boreal steppe, indicating that irrespective of the climate, the quantification method and the length of the experiment PyOM has a MRT ranging in the centennials, when measured in field conditions. On the other hand in a 2-year field experiment carried out in a plant-soil system in a tropical savanna, Major et al. (2010) found a turnover time of 89 years. However, in their experiment the presence of rhizodeposition, due to the increase in biomass (observed in the first year) following PyOM addition, may have primed the PyOM mineralization. In fact, easily decomposable compounds like glucose or rhizodeposition can increase the PyOM mineralization rate, since enzymes produced for their mineralization can also contribute to the mineralization of PyOM (Hamer et al., 2004; Kuzyakov et al., 2009). A similar effect was observed by Keith et al. (2011), who found an increase in PyOM mineralization as a result of the addition of fresh organic matter to the soil. Nonetheless, we believe that the exclusion of living roots, together with the ecological conditions present of the forest gap where the present experiment simulates post-fire forest conditions on the short term.

Gurwick et al. (2013) reviewed field studies on PyOM losses, and observed that there are examples displaying PyOM loss rate in the range of decadal, centennial and millennia scales. Our results indicate that PyOM turns over on a centennial timescale.

The PyOM mineralization rate did not decrease significantly with time (Fig. 3). In incubation experiments Kuzyakov et al. (2009) and Maestrini et al. (2014b), found that ryegrass-derived PyOM mineralization rates decreased over the first 2 to 3 months before levelling off. Likewise, in an incubation in quartz medium, the PyOM mineralization rate was twice as fast in the first month as in the second month (Hamer et al., 2004). In our experiment, PyOM mineralization rate tended to decrease (not significantly) over the first 3 weeks, and increased in summer, suggesting that temperature might have influenced PyOM mineralization (Fang et al., 2014). However the set-up of our study did not allow distinguishing between the effect of the season and of time.

The fraction of PyOM-derived $\mathrm{C}$ in the soil respiration did not vary along the time of mineralization (Fig. 2a). The fraction was higher for the first three sampling dates, but rapidly levelled off. This confirms findings from Smith et al. (2010) who observed that the PyOM fraction in soil respiration rapidly decreased over 1 week in an incubation experiment. Using the fraction derived from PyOM as an indicator for PyOM decay relative to native soil organic carbon, our study indicates that the stability of PyOM relative to native soil organic $\mathrm{C}$ was constant over time, and was not affected by the higher temperature, not confirming the theory proposed by Hartley and Ineson (2008) on the higher temperature sensitivity of resistant organic matter. Cumula- tive wood mineralization after 1 year was equal to $22 \%$ of the initially added wood-C. On the same site Kammer and Hagedorn (2011) found similar values for beech twigs, with $22-26 \%$ mineralization over 1 year at the soil surface. Using the same substrate, Santos et al. (2010) found wood mineralization of $22 \%$ in an andesitic soil and $30 \%$ in a granitic soil over 180 days, while in our study only $10 \%$ of the initially added wood-C was mineralized over the same period; these results confirm that similar to the PyOM, the mineralization of wood-C is slower under field conditions than in laboratory incubation experiments. The fraction of total soil respiration coming from wood decreased with time (Fig. 2 b). This agrees with findings from Kammer et al. (2011).

We predicted the ratio between the PyOM-C remaining in soil and the one remaining in its parent material (wood) over 5 years using Eq. (8) and found that their ratio would be greater than 1 after 2 years. This may have important implications when computing the $\mathrm{C}$ budget of post-fire sites, stressing the risk of an overestimation of the losses by forest fires when PyOM is not taken into account. Nonetheless caution should be used when applying this indicator, as it does not take into account the influence of fire events on plant growth.

\subsection{Priming effect}

We did not observe a significant change in native soil organic $\mathrm{C}$ mineralization due to the addition PyOM or wood (Fig. 4).

Singh et al. (2014) measured the recovery of total native soil organic $\mathrm{C}$ in the same experiment after 10 months and observed no significant changes in the soil organic $\mathrm{C}$ content, but observed a decrease in the free light fraction $\mathrm{C}$ content with added PyOM compared with the unamended control treatments.

Furthermore, neither Abiven and Andreoli (2010) who incubated PyOM and litter in the same soil, nor Santos et al. (2012) who incubated the same substrate in different soils, observed a priming effect in either experiment.

Maestrini et al. (2014) conducted a meta-analysis on priming effect induced by PyOM on the short term and found that a short-term positive priming effect is reported in most of the cases. Singh and Cowie (2014) observed a correlation between the short-term priming effect induced by PyOM and the quantity of labile $C$ present in PyOM, determined using a two-pool model.

The quantity of labile $C$ present in our PyOM, determined by using as a proxy for labile $\mathrm{C}$ the two pool model derived from an incubation experiment (Santos et al., 2012) was similar to the quantity of labile $C$ present in the wood-derived PyOM pyrolysed at $550{ }^{\circ} \mathrm{C}$ used by Singh and Cowie (2014) (1.1-1.5 vs. $1.3 \mathrm{mg} \mathrm{Cg}$ PyOM-C added). In both cases this addition did not induce a priming effect when measured as $\mathrm{CO}_{2}$ efflux. Therefore our results suggest that a short-term priming effect induced by added PyOM may be caused by the presence of labile $C$ in PyOM. 
Luo et al. (2011) suggested that the increase in $\mathrm{pH}$ following from PyOM addition may contribute to the positive priming effect induced by PyOM. In the present experiment, soil $\mathrm{pH}$ did not differ between PyOM and control treatment 10 months after the addition of the substrate (personal communication). Nonetheless we cannot rule out the hypothesis that PyOM temporarily increased the $\mathrm{pH}$ of soil at the beginning of the experiment, as observed in Maestrini et al. (2014b).

In a field experiment Major et al. (2010) found that PyOM addition increased native soil organic $\mathrm{C}$ respiration and attributed it to soil respiration following from the increased root respiration due to the increased plant productivity in the presence of PyOM.

In the present experiment, it is possible that PyOM triggered the activity of microbes which increased the mineralization of the accessible organic matter (the free light fraction), but that this change was too small to be observed in the native organic-matter-derived $\mathrm{CO}_{2}$ or in the bulk native soil organic matter recovery after 10 months.

\subsection{Dissolved organic carbon}

In our study, the loss of PyOM-C and wood-C as DOC were 3 orders of magnitude lower than their respective losses as $\mathrm{CO}_{2}$ after 1 year $(0.0004 \%$ vs. $0.5 \%$ and $0.02 \%$ vs. $22 \%$ of the initially applied PyOM-C and wood-C, respectively; Supplement Fig. S3). The losses of wood-C as DOC were 50 times higher than the DOC losses of PyOM.

Singh et al. (2014) observed a vertical downward translocation of PyOM and wood of $126 \mathrm{~mm}_{\text {year }}{ }^{-1}$, however Singh et al. did not characterize the chemical composition of the leached PyOM-derived material or predict if the translocated PyOM would accumulate or be further transported downward. Our results indicate that losses as DOC were negligible and that major losses of PyOM to groundwater are not likely to occur on the short term.

In a field study in a savannah Oxisol, Major et al. (2010) found that DOC losses were $0.003 \%$ of the initial PyOM$\mathrm{C}$ at a depth of $15 \mathrm{~cm}$, i.e. 10 times higher than observed in the present study. This discrepancy can be partially explained by the different operational definition of DOC used in the two studies. While Major et al. (2010) considered DOC particles with a size $<0.7 \mu \mathrm{m}$, we considered DOC particles with a size $<0.45 \mu \mathrm{m}$. Major et al. (2010) found that PyOM additions increased the flux of soil water, but we observed no such increase in our study. The effect seen by Major et al. (2010) may have been because their PyOM application rate was 6 times higher than in our study. Also the rainfall regime of their site, characterized by high and concentrated annual rainfall, certainly contributed to increase the level of PyOM lost by leaching compared with our temperate forest where rainfall is much lower. Finally, Major et al. (2010) studied the movement of PyOM in a sandy Oxisol that is characterized by high water infiltration rates (Major et al., 2010; Soil Survey Stuff, 1999), while the soil in our field site was rich in clay that may have prevented water from quickly percolating through the soil profile. As predicted, soil physical properties are important controllers of the leaching rate of PyOM as DOC. A similar conclusion was drawn by Leifeld et al. (2007) who observed consistent vertical movements of PyOM along the profile of three grassland soils (21-69\% of PyOM-C moved below $30 \mathrm{~cm}$ over 50 years). They suggested that such high vertical movement is due to the high hydraulic conductivity of the soil, which is characterized by high porosity, as it was formerly a peatland.

Our findings on limited losses of PyOM-derived DOC confirmed previous studies, showing that only a small portion of fresh PyOM was soluble in water (Abiven et al., 2011). However, the soluble fraction of PyOM may increase with the degree of surface oxidation and ageing of PyOM (Hockaday et al., 2006; Abiven et al., 2011). Alternatively, it is possible that part of the dissolved PyOM is adsorbed in the surface layers of the soil, characterized by high clay content, and may be released in the following years. Therefore, due to PyOM ageing and partial release of the PyOM adsorbed on clay minerals, it is reasonable to expect that larger proportions of PyOM will be released as DOC in the future.

In a nearby experiment, Kammer et al. (2011) observed wood losses as DOC equivalent to $1.5 \%$ of initially applied wood-C over 1 year; however, in their experiment wood was applied on the soil surface and therefore directly exposed to the rainfall, while in our case wood was incorporated in the first centimetres of the soil. Moreover, they observed that wood-derived DOC strongly decreased from the litter layer to $5 \mathrm{~cm}$ depth. Such a decrease of DOC fluxes along the vertical soil profile indicates that the adsorption of DOC on mineral surfaces could be an important mechanism in preventing the wood-derived DOC from percolating down to $15 \mathrm{~cm}$ (Kaiser and Guggenberger, 2000).

\subsection{Effect of Nitrogen addition}

The addition of $\mathrm{N}$ had a significant effect on PyOM loss as $\mathrm{CO}_{2}$ only on one sampling date (Fig. 3). However, $\mathrm{N}$ decreased the cumulative PyOM-C mineralization by $47 \%$ after 1 year (Supplement Fig. S2; Table 2) but had no effect on cumulative wood mineralization.

Singh et al. (2014) measured the recovery of PyOM-C in the same experiment and found that PyOM recovery did not differ significantly between the treatment under ambient and increased $\mathrm{N}$. In our paper, we were able to have a more direct measurement of PyOM-C loss as $\mathrm{CO}_{2}$. Thus, with better resolution, we were able to quantify the $\mathrm{N}$ effect that was not possible when looking at soil recovery in Singh et al. (2014).

Santos et al. (2012) incubated the same wood and PyOM in sub-soils from CA, USA, and found no effect of $\mathrm{N}$ addition on PyOM or wood mineralization. These contrasting results from added $\mathrm{N}$ may be explained by the differences in experimental conditions. In our experiment we had 3 times lower $\mathrm{N}$ addition level, added monthly to the soil, while Santos et 
al. (2012) added $\mathrm{N}$ in a single addition at the beginning of the experiment. Soil properties, including the content and composition of organic C, may also play a role. Santos et al. (2012) suggested that part of the added ammonium-N may have been adsorbed in the interlayer of the vermiculite present in their soil, preventing it from being available to microbes.

Carreiro et al. (2000) and Sinsabaugh (2010) observed that $\mathrm{N}$ addition decreased phenol-oxidase and peroxidase activities in surface soils. The oxidative enzymes are required for the cleavage of aromatics, and thus should be strong controllers of the breakdown of PyOM. However Maestrini et al. (2014b) incubated soil from the same site of the present experiment and did not observe an effect of $\mathrm{N}$ on potential phenol-oxidase activity. The results from Maestrini et al. (2014b) therefore do not confirm this hypothesis.

Also the "N mining" theory (Craine et al., 2007) may explain our results on the decrease of PyOM mineralization under increased $\mathrm{N}$. In this view, $\mathrm{N}$ additions can depress the mineralization of SOM and litter by fulfilling the $\mathrm{N}$ demand of microbes "mining" the recalcitrant fraction of the substrate to obtain available N. Such mining activity should result either in an increase of $\mathrm{N}$ mineralization from the substrate, or in a higher incorporation of substrate-derived $\mathrm{N}$ in the microbial biomass. However Santos et al. (2014) did not observe a difference in PyOM N-derived mineral $\mathrm{N}$ under ambient and increased N. Furthermore Singh et al. (2014) were not able to observe any PyOM-derived $\mathrm{N}$ in the microbial biomass after 10 months in the field. Therefore results from the two studies above do not confirm the $\mathrm{N}$ mining hypothesis. In general, comparisons among soils can be challenging as the content and composition of SOM is a critical factor in if and in what manner added $\mathrm{N}$ affects SOC or litter mineralization rates (Knorr et al., 2005).

Wood loss as $\mathrm{CO}_{2}$ or DOC was not affected by $\mathrm{N}$ deposition. This result is consistent with Santos et al. (2012) using the same wood litter. In contrast, Hagedorn et al. (2003), who measured beech twig mineralization in a neighbouring site, found that $\mathrm{N}$ addition depressed wood mineralization from 6 to 12 months after $\mathrm{N}$ addition (i.e. in the same time frame of $\mathrm{N}$ addition in our experiment). Berg and Matzner (1997) noted in their review that such pattern of early and late stage effect of $\mathrm{N}$ on litter mineralization had been observed across several studies. Such contrasting results may be explained by the shorter duration of $\mathrm{N}$ addition in our experiment, 6 months instead of 1 year, therefore supporting findings of Knorr et al. (2005) who observed that the effect of $\mathrm{N}$ addition on litter mineralization was extremely low when lasting for less than 6 months.

\section{Conclusions}

We added ${ }^{13} \mathrm{C}$-labelled PyOM or pine wood to a temperate forest soil with and without added inorganic N. In the first year we observed that:

- PyOM-C mineralized at a rate of $0.5 \%$ of applied $C$.

- PyOM losses as dissolved organic carbon (DOC) were 3 orders of magnitude smaller than their losses as $\mathrm{CO}_{2}$.

- $\mathrm{N}$ addition depressed the mineralization of PyOM by $43 \%$ but did not alter wood mineralization, nor the losses by leaching from wood or PyOM.

- There was no significant increase in soil $\mathrm{CO}_{2}$ respiration of native SOC after PyOM or wood was added to the soil.

Therefore, we conclude that this pine-derived PyOM-C has a centennial-scale MRT. Also we conclude that the predicted increases in $\mathrm{N}$ deposition in the future can decrease PyOM mineralization and that mineralization to $\mathrm{CO}_{2}$ is the main process leading to PyOM losses in the first after PyOM addition.

\section{The Supplement related to this article is available online at doi:10.5194/bg-11-5199-2014-supplement.}

Acknowledgements. The Swiss National Science Foundation (SNSF) financially supported this study. This work was also supported by the Director, Office of Science, Office of Biological and Environmental Research, Climate and Environmental Science Division, of the US Department of Energy under Contract No. DE-AC02- 05CH11231 to Berkeley Laboratory. This study was supported by the University of Zurich Research Priority Program (URPP) "Global Change and Biodiversity". We thank Sarah Bosch and Ryan Christinger for their help in setting the experimental field plots, Marisa Brauchli, Charlotte Huber, Verena Lanny, Fabian Zust and Stefanie Mueller for the help in field measurement, and Ivan Woodhatch for the technical help and support in the set-up. We also thank Michael Hilf, Bruno Kaegi, and Claudia Schreiner for their assistance in various laboratory analyses carried out at the University of Zurich. We further extend our thanks to Noureddine Hajjar for support in TOC analysis at the Institute for Forest, Snow and Landscape research (WSL). We would also like to acknowledge Rolf Siegwolf, Matthias Saurer, and Catharina Lotscher for support in the isotope analysis at Paul Scherrer Institute (PSI), Switzerland. We are also extremely grateful to the reviewers who helped to improve the manuscript as well as the authors of the online comments on an early version of the manuscript.

Edited by: R. Bol 


\section{References}

Abiven, S. and Andreoli, R.: Charcoal does not change the decomposition rate of mixed litters in a mineral cambisol: a controlled conditions study, Biol. Fertil. Soil., 47, 111-114, 2010.

Abiven, S., Hengartner, P., Schneider, M., Singh, N., and Schmidt, M. W. I.: Pyrogenic carbon soluble fraction is larger and more aromatic in aged charcoal than in fresh charcoal, Soil Biol. Biochem., 43, 1615-1617, 2011.

Balesdent, J. and Mariotti, A.: Mass spectrometry of soils, in: Mass Spectrometry of Soils, edited by: Boutton, T. W. and Yamasaki, S. I., Marcel Dekker, New York, 1996.

Bebber, D. P., Watkinson, S. C., Boddy, L., and Darrah, P. R.: Simulated nitrogen deposition affects wood decomposition by cordforming fungi, Oecologia, 167, 1177-84, 2011.

Berg, B. and Matzner, E.: Effect of $\mathrm{N}$ deposition on decomposition of plant litter and soil organic matter in forest systems, Environ. Rev., 5, 1-25, 1997.

Bird, J. A. and Torn, M. S.: Fine roots vs. needles: a comparison of $13 \mathrm{C}$ and $15 \mathrm{~N}$ dynamics in a ponderosa pine forest soil, Biogeochemistry, 79, 361-382, 2006.

Bird, M. I., Moyo, C., Veenendaal, E. M., Lloyd, J., and Frost, P.: Stability of elemental carbon in a savanna soil, Global Biogeochem. Cy., 13, 923-932, 1999.

Burton, A. J., Pregitzer, K. S., Crawford, J. N., Zogg, G. P., and Zak, D. R.: Simulated chronic NO3- deposition reduces soil respiration in northern hardwood forests, Glob. Change Biol., 10, 10801091, 2004.

Carreiro, M. M., Sinsabaugh, R. L., Repert, D. A., and Parkhust, D. F.: Microbial enzyme shift explain litter decay responses to simulated Nitrogen deposition, Ecology, 81, 2359-2365, 2000.

Chatterjee, S., Santos, F., Abiven, S., Itin, B., Stark, R. E., and Bird, J. A.: Elucidating the chemical structure of pyrogenic organic matter by combining magnetic resonance, mid-infrared spectroscopy and mass spectrometry, Organ. Geochem., 51, 35-44, 2012.

Craine, J. M., Morrow, C., and Fierer, N.: Microbial nitrogen limitation increases decomposition, Ecology, 88, 2105-13, 2007.

Cross, A. and Sohi, S. P.: The priming potential of biochar products in relation to labile carbon contents and soil organic matter status, Soil Biol. Biochem., 43, 2127-2134, 2011.

Dittmar, T.: The molecular level determination of black carbon in marine dissolved organic matter, Organ. Geochem., 39, 396-407, 2008.

Fang, C. and Moncrieff, J. B.: The dependence of soil $\mathrm{CO}_{2}$ efflux on temperature, Soil Biol. Biochem., 33, 155-165, 2001.

Fang, Y., Singh, B., Singh, B. P., and Krull, E.: Biochar carbon stability in four contrasting soils, Europ. J. Soil Sci., 65, 60-71, 2014.

Frey, S. D., Knorr, M., Parrent, J. L., and Simpson, R. T.: Chronic nitrogen enrichment affects the structure and function of the soil microbial community in temperate hardwood and pine forests, Forest Ecol. Manage., 196, 159-171, 2004.

Goldberg, D.: Black carbon in the environment, Wiley and Sons, 1985.

Gurwick, N. P., Moore, L., Kelly, C., and Elias, P.: A systematic review of biochar research, with a focus on its stability in situ and its promise as a climate mitigation strategy, Plos One, 8, e75932, doi:10.1371/journal.pone.0075932, 2013.
Hagedorn, F., Kammer, A., Schmidt, M. W. I., and Goodale, C. L.: Nitrogen addition alters mineralization dynamics of ${ }^{13} \mathrm{C}$ depleted leaf and twig litter and reduces leaching of older DOC from mineral soil, Glob. Change Biol., 18, 1412-1427, 2012.

Hagedorn, F., Spinnler, D., and Siegwolf, R.: Increased N deposition retards mineralization of old soil organic matter, Soil Biol. Biochem., 35, 1683-1692, 2003.

Hamer, U., Marschner, B., Brodowski, S., and Amelung, W.: Interactive priming of black carbon and glucose mineralisation, Organ. Geochem., 35, 823-830, 2004.

Hammes, K., Torn, M. S., Lapenas, A. G., and Schmidt, M. W. I.: Centennial black carbon turnover observed in a Russian steppe soil, Biogeosciences, 5, 1339-1350, doi:10.5194/bg-51339-2008, 2008.

Hartley, I. P. and Ineson, P.: Substrate quality and the temperature sensitivity of soil organic matter decomposition, Soil Biol. Biochem., 40, 1567-1574, 2008.

Herath, H. M. S. K., Camps-Arbestain, M., Hedley, M. J., Kirschbaum, M. U. F., Wang, T., and van Hale, R.: Experimental evidence for sequestering $\mathrm{C}$ with biochar by avoidance of $\mathrm{CO}_{2}$ emissions from original feedstock and protection of native soil organic matter, GCB Bioenergy, doi:10.1111/gcbb.12183, 2014.

Hilscher, A., Heister, K., Siewert, C., and Knicker, H.: Mineralisation and structural changes during the initial phase of microbial degradation of pyrogenic plant residues in soil, Organ. Geochem., 40, 332-342, 2009.

Hilscher, A. and Knicker, H.: Degradation of grass-derived pyrogenic organic material, transport of the residues within a soil column and distribution in soil organic matter fractions during a 28 month microcosm experiment, Organ. Geochem., 42, 42-54, 2011.

Hockaday, W. C., Grannas, A. M., Kim, S., and Hatcher, P. G.: Direct molecular evidence for the degradation and mobility of black carbon in soils from ultrahigh-resolution mass spectral analysis of dissolved organic matter from a fire-impacted forest soil, Organ. Geochem., 37, 501-510, 2006.

Janssens, I. A., Dieleman, W., Luyssaert, S., Subke, J.-A., Reichstein, M., Ceulemans, R., Ciais, P., Dolman, A.J., Grace, J., Matteucci, G., Papale, D., Piao, S. L., Schulze, E.-D., Tang, J., and Law, B. E.: Reduction of forest soil respiration in response to nitrogen deposition, Nat. Geosci., 3, 315-322, 2010.

Joos, O., Saurer, M., Heim, A., Hagedorn, F., Schmidt, M. W. I., and Siegwolf, R. T. W.: Can we use the $\mathrm{CO}_{2}$ concentrations determined by continuous-flow isotope ratio mass spectrometry from small samples for the Keeling plot approach?, Rapid Communications in Mass Spectrometry, 22, 4029-4034, 2008.

Kaiser, K. and Guggenberger, G.: The role of DOM sorption to mineral surfaces in the preservation of organic matter in soils, Organ. Geochem., 31, 711-725, 2000.

Kammer, A. and Hagedorn, F.: Mineralisation, leaching and stabilisation of ${ }^{13} \mathrm{C}$-labelled leaf and twig litter in a beech forest soil, Biogeosciences, 8, 2195-2208, doi:10.5194/bg-8-21952011, 2011.

Kammer, A., Schmidt, M. W. I., and Hagedorn, F.: Decomposition pathways of 13C-depleted leaf litter in forest soils of the Swiss Jura, Biogeochem., 108, 395-411, 2011.

Keeling, C. D.: The concentration and isotopic abundances of atmospheric carbon dioxide in rural areas, Geochim. Cosmochim. Acta, 13, 322-324, 1958. 
Keith, A., Singh, B., and Singh, B. P.: Interactive priming of biochar and labile organic matter mineralization in a smectite-rich soil., Environ. Sci. Technol., 45, 9611-8, 2011.

Kim, S., Kaplan, L. A., Benner, R., and Hatcher, P. G.: Hydrogendeficient molecules in natural riverine water samples - evidence for the existence of black carbon in DOM, Mar. Chem., 92, 225234, 2004.

Knorr, M., Frey, S. D., and Curtis, P. S.: Nitrogen additions and litter decomposition: a meta-analysis, Ecology, 86, 3252-3257, 2005.

Kuzyakov, Y., Subbotina, I., Chen, H., Bogomolova, I., and Xu, X.: Black carbon decomposition and incorporation into soil microbial biomass estimated by ${ }^{14} \mathrm{C}$ labeling, Soil Biol. Biochem., 41, 210-219, 2009.

Lehmann, J., Rillig, M. C., Thies, J., Masiello, C. A., Hockaday, W. C., and Crowley, D.: Biochar effects on soil biota - A review, Soil Biol. Biochem., 43, 1812-1836, 2011.

Leifeld, J., Fenner, S., and Müller, M.: Mobility of black carbon in drained peatland soils, Biogeosciences, 4, 425-432, doi:10.5194/bg-4-425-2007, 2007.

Liang, B., Lehmann, J., Sohi, S. P., Thies, J. E., O’Neill, B., Trujillo, L., Gaunt, J., Solomon, D., Grossman, J., Neves, E. G., and Luizão, F. J.: Black carbon affects the cycling of non-black carbon in soil, Organ. Geochem., 41, 206-213, 2010.

Liang, B., Lehmann, J., Solomon, D., Kinyangi, J., Grossman, J., O’Neill, B., Skjemstad, J. O., Thies, J., Luizão, F. J., Petersen, J., and Neves, E. G.: Black Carbon Increases Cation Exchange Capacity in Soils, Soil Sci. Soc. Am. J., 70, 1719, doi:10.1016/j.orggeochem.2009.09.007, 2006.

Luo, Y., Durenkamp, M., De Nobili, M., Lin, Q., and Brookes, P. C.: Short term soil priming effects and the mineralisation of biochar following its incorporation to soils of different $\mathrm{pH}$, Soil Biol. Biochem., 43, 2304-2314, 2011.

Maestrini, B., Nannipieri, P., and Abiven, S.: A meta-analysis on pyrogenic organic matter induced priming effect, GCB Bioenergy, doi:10.1111/gcbb.12194, 2014.

Maestrini, B., Herrmann, A. M., Nannipieri, P., Schmidt, M. W. I., and Abiven, S.: Ryegrass-derived pyrogenic organic matter changes organic carbon and nitrogen mineralization in a temperate forest soil, Soil Biol. Biochem., 69, 291-301, 2014b.

Major, J., Lehmann, J., Rondon, M., and Goodale, C.: Fate of soilapplied black carbon: downward migration, leaching and soil respiration, Glob. Change Biol., 16, 1366-1379, 2010.

Moritz, M., Parisien, M., Batllori, E., Krawchuk, M. A., Van Dorn, J., Ganz, D. J., and Hayhoe, K.: Climate change and disruptions to global fire activity, Ecosphere, 3, 1-22, 2012.

Ngao, J., Epron, B., Brechet, C., and Granier, A.: Estimating the contribution of leaf litter decomposition to soil $\mathrm{CO}_{2}$ efflux in a beech forest using ${ }^{13} \mathrm{C}$-depleted litter, Glob. Change Biol., 11, 1768-1776, 2005.

Nguyen, B. T., Lehmann, J., Kinyangi, J., Smernik, R., Riha, S. J., and Engelhard, M. H.: Long-term black carbon dynamics in cultivated soil, Biogeochemistry, 89, 295-308, 2008.

Pataki, D. E.: The application and interpretation of Keeling plots in terrestrial carbon cycle research, Global Biogeochem. Cy., 17, 22, doi:10.1029/2001GB001850, 2003.
Pregitzer, K. S., Burton, A. J., Zak, D. R., and Talhelm, A. F.: Simulated chronic nitrogen deposition increases carbon storage in Northern Temperate forests, Glob. Change Biol., 14, 143-153, 2008.

Ruehr, N. K., Knohl, A., and Buchmann, N.: Environmental variables controlling soil respiration on diurnal, seasonal and annual time-scales in a mixed mountain forest in Switzerland, Biogeochemistry, 98, 153-170, 2009.

Rumpel, C., Chaplot, V., Planchon, O., Bernadou, J., Valentin, C., and Mariotti, A.: Preferential erosion of black carbon on steep slopes with slash and burn agriculture, Catena, 65, 30-40, 2006.

Santos, F., Torn, M. S., and Bird, J. A.: Biological degradation of pyrogenic organic matter in temperate forest soils, Soil Biol. Biochem., 51, 115-124, 2012.

Schmidt, M. W. I. and Noack, A.: Black carbon in soils and sediments: Analysis, distribution, implications, and current challenges, Global Biogeochem. Cy., 14, 777-793, 2000.

Schmidt, M. W. I., Skjemstad, J. O., Gehrt, E., and Ko, I.: Charred organic carbon in German chernozemic soils, Europ. J. Soil Sci., 50, 351-365, 1999.

Schmidt, M. W. I., Torn, M. S., Abiven, S., Dittmar, T., Guggenberger, G., Janssens, I., Kleber, M., Kögel-Knabner, I., Lehmann, J., Manning, D., Nannipieri, P., Rasse, D. P., Weiner, S., and Trumbore, S. E.: Persistence of soil organic matter as an ecosystem property, Nature, 478, 49-56, 2011.

Singh, B. P. and Cowie, A. L.: Long-term influence of biochar on native organic carbon mineralisation in a low-carbon clayey soil, Scient. Reports, 4, 3687, doi:10.1038/srep03687, 2014.

Singh, B. P., Cowie, A. L., and Smernik, R. J.: Biochar carbon stability in a clayey soil as a function of feedstock and pyrolysis temperature, Environ. Sci. Technol., 46, 11770-11778, 2012 b.

Singh, N., Abiven, S., Maestrini, B., Bird, J., Torn, M. S., and Schmidt, M. W. I.: Transformation and stabilization of pyrogenic organic matter in a temperate forest field experiment, Glob. Change Biol., 20, 1629-1642, 2014.

Singh, N., Abiven, S., Torn, M. S., and Schmidt, M. W. I.: Fire-derived organic carbon in soil turns over on a centennial scale, Biogeosciences, 9, 2847-2857, doi:10.5194/bg-9-28472012, 2012.

Sinsabaugh, R. L.: Phenol oxidase, peroxidase and organic matter dynamics of soil, Soil Biol. Biochem., 42, 391-404, 2010.

Smith, J. L., Collins, H. P., and Bailey, V. L.: The effect of young biochar on soil respiration, Soil Biol. Biochem., 42, 2345-2347, 2010.

Soil Survey Stuff: Soil taxonomy: A basic system of soil classification for making and interpreting soil surveys., Washington DC, 1999.

Torn, M. S., Davis, S., Bird, J. A., Shaw, M. R., and Conrad, M. E.: Automated analysis of ${ }^{13} \mathrm{C} /{ }^{12} \mathrm{C}$ ratios in $\mathrm{CO}_{2}$ and dissolved inorganic carbon for ecological and environmental applications, Rapid Communications in mass spectrometry, 17, 267582, 2003.

Wardle, D. A., Nilsson, M.-C., and Zackrisson, O.: Fire-derived charcoal causes loss of forest humus, Science, 320, 629, doi:10.1126/science.1154960, 2008.

Westerling, A. L., Hidalgo, H. G., Cayan, D. R., and Swetnam, T. W.: Warming and earlier spring increase western US forest wildfire activity, Science (New York, NY), 313, 940-943, 2006. 
Yarnes, C., Santos, F., Singh, N., Abiven, S., Schmidt, M. W. I., and Bird, J.: Stable isotopic analysis of pyrogenic organic matter in soils by liquid chromatography-isotope-ratio mass spectrometry of benzene polycarboxylic acids, Rapid Communications in Mass Spectrometry, 25, 3723-3731, 2011.
Ziolkowski, L. A. and Druffel, E. R. M.: Aged black carbon identified in marine dissolved organic carbon, Geophys. Res. Lett., 37, 4-7, 2010. 